\title{
An Input-Output Pollution Control Model and Product Selection
}

\author{
Aniekan Ebiefung ${ }^{1} \&$ Idongesit Isaac ${ }^{2}$ \\ ${ }^{1}$ Department of Mathematics, University of Tennessee, Chattanooga, USA \\ ${ }^{2}$ Idongesit Isaac, Department of Mathematics, Statistics, and Computer Science, University of Calabar, Nigeria \\ Correspondence: Aniekan Ebiefung, Department of Mathematics, University of Tennessee, Chattanooga, TN \\ 37403, USA. E-mail: Aniekan-Ebiefung@utc.edu
}

Received: July 19, 2012 Accepted: August 6, 2012 Online Published: September 11, 2012

doi:10.5539/jmr.v4n5p1 URL: http://dx.doi.org/10.5539/jmr.v4n5p1

\begin{abstract}
An input-output pollution control model is provided. It describes the flow of pollutants through all sectors of the economy. It allows each sector to evaluate the level of pollutants generated by different manufacturing processes simultaneously, and to select and produce a product that emits pollutants within some permissible limits. For a given amount of pollutants emitted by a sector, a method for computing the corresponding number of items to be produced by that sector is provided.
\end{abstract}

Keyword: linear programming, input-output, pollution control, environment, Leontief models, product selection

\section{Introduction}

Input-Output (I-O) techniques, developed by Leontief in the 1930's, describe the inter-relationship among different sectors of the economy. Its areas of applications are manifold. Leontief (1985) used the model to address issues relating to the choice of technology. Ebiefung and Kostreva (1993; 2003) generalized the model and applied it to the problem of choice of technology, production equilibrium point, and showed equivalence to a vertical linear complementarity problem.

The use of I-O techniques to address environmental issues dates back to the 1960's. Examples of the use of I-O techniques to address environmental problems have been demonstrated by Daly (1968), Leontief (1970), Leontief and Daniel Ford (1972) and Victor (1972a; 1972b). Some recent developments in the use of input-output techniques to address environmental issues involve augmentation or modification of earlier models. These have been revealed in the studies by Steenge (1999) and Moore (1981). The monographs by Miller and Blair (1985) and Raa (1995) give excellent summaries of applications of the input-output techniques that address environmental issues.

We are motivated for this study by the following observations. The production of one unit of an item leads to emission of pollutants into the environment. The amount and type of pollutants emitted vary according to goods and technology. Suppose $k$ products satisfy all the criteria for production required by a sector of the economy. If the sector can only produce one of these $\mathrm{k}$ items, it makes sense to select and manufacture one whose pollutants' emission is not above some specified limit. In this paper, we provide an input-output pollution model that each sector of the economy can use to select and produce an item that meets specified pollution standard. This model uses only pollution input-output "technology matrix", while many other models use both pollution input-output technology matrix and production input-output technology matrix. The validity of this model is demonstrated by using it to solve an example equivalent to that of Leontief (1970).

The structure of the rest of the paper is as follows. In Section 2, the I-O pollution model is formulated. In Section 3 , we provide conditions for existence of solutions for the new pollution model. In Section 4, we provide a technique for computing production quantities. Concluding remarks are given in Section 5.

\section{The Input-Output Pollution Model}

We start with the following notation.

\section{Constants:}

$n=$ number of sectors in the economy.

$m_{j}=$ number of different types of products that sector $\mathrm{j}$ can produce, $j=1, \ldots, n$. 
$x_{j}=$ amount of pollutants to be produced by sector $j, j=1, \ldots, n$.

$b^{j}=$ amount of pollutants that sector $j$ should produce in order to satisfy external demands, $j=1, \ldots, n$.

$a_{i k}^{j}=$ output of pollutants by product $i$ in sector $j$ needed by sector $k$ to produce one unit of its pollutants, $i=$ $1, \ldots, m_{j}, j, k=1, \ldots, n$.

\section{Matrices:}

For each $j, j=1, \ldots, n$, let $A^{j}=\left(a_{i k}^{j}\right), i=1, \ldots, m_{j}, k=1, \ldots, n . E^{j}=$ an $m_{j} \times n$ matrix with 1 s in column $j$ and zeros in all other columns.

$$
\begin{gathered}
q^{j}=\left[\begin{array}{c}
b^{j} \\
\cdot \\
\cdot \\
\cdot \\
b^{j}
\end{array}\right], q=\left[\begin{array}{c}
q^{1} \\
\cdot \\
\cdot \\
\cdot \\
q^{n}
\end{array}\right], A=\left[\begin{array}{c}
A^{1} \\
\cdot \\
\cdot \\
\cdot \\
A^{n}
\end{array}\right], \\
E=\left[\begin{array}{c}
E^{1} \\
\cdot \\
\cdot \\
\cdot \\
E^{n}
\end{array}\right], x=\left[\begin{array}{c}
x_{1} \\
\cdot \\
\cdot \\
\cdot \\
x_{n}
\end{array}\right] .
\end{gathered}
$$

If we set $m=m_{1}+m_{2}+\ldots+m_{n}$, then $E \in R^{m \times n}, A \in R^{m \times n}, q \in R^{m}, x \in R^{n}$, and $q^{j} \in R^{m_{j}}$.

The matrix $A^{j}$ represents the pollution matrix for sector $j$, and $A$ the pollution matrix for the whole economy.

The I-O Pollution Model (IOPM): Given the input-output pollution coefficient matrix $A$ and the amount of pollutants $q$ required by all sectors of the economy to meet external demands, find $x$, the amount of pollutants to be produced by all sectors of the economy so that

$$
\begin{gathered}
\text { IOPM : } \quad\left(E^{j}-A^{j}\right)_{i} x=q_{i}^{j}, j=1, \ldots, n, \\
q_{i}^{j} \geq 0, i \in\left\{1, \ldots, m_{j}\right\} \\
x \geq 0
\end{gathered}
$$

The product chosen for production by sector $\mathrm{j}$ is one whose row satisfies Equations (3-5). If many rows from sector $\mathrm{j}$ satisfy Equations (3-5), then sector $\mathrm{j}$ can produce any of those products, the selection of which may depend on other considerations.

Remark The case of $m_{j}=1, j=1, \ldots, n$, assumes that each sector produces only one product, which may be an aggregate value as is usually assumed in some input-output models. In this case, $E=I$, the $n \times n$ identity matrix, $A$ is a square matrix of size $n$, and $q$ is a column vector of $n$ components.

\section{Existence of Solutions and Solvability of the I-O Pollution Model}

We start with definitions.

Definition 1 Let $M$ be an $n \times n$ matrix. We call $M$ a representative sub-matrix of $E-A$ if row $j$ of $M$ is from row i of $E^{j}-A^{j}, i \in\left\{1, \ldots, m_{j}\right\}$. We call $E^{j}-A^{j}$ the $j$ th block of $E-A$. The number of representative sub-matrices is $\prod_{j=1}^{n} m_{j}$.

Definition 2 An $m \times n$ matrix $N$, with $m \geq n$, is called a vertical block $\Theta$-matrix if each representative sub-matrix of $N$ is a square $\Theta$-matrix. Since $A \geq 0$, the matrix $E-A$ is a vertical block Z-matrix (Horn \& Johnson, 1991).

Notation If $A$ is an $m \times n$ matrix, we will use $A_{j}$ to denote row $j$ of $A$.

\section{Algorithm}

Step 1: Let $M$ be a representative sub-matrix of $E-A$. Let $\bar{q}$ be a column vector with n components obtained from $q$ such that row $j$ of $\bar{q}$ corresponds to row $j$ of $M$.

Step 2: Solve the linear system:

$$
M \bar{x}=\bar{q}, \bar{x} \geq 0
$$

Step 3: If the system in Step 2 has a solution $\bar{x}$, then $\bar{x}$ solves the pollution model. If for all $M$, the system in Step 2 has no solution, then the pollution model is infeasible. 
The following theorem proves the validity of the Algorithm.

Theorem 1 The vector $\bar{x} \geq 0$ solves Equations (3-5) if and only if there is a representative sub-matrix $M$ of $E-A$ and a vector $\bar{q}$ obtained from $q$, whose rows conform to the rows in $M$, such that $M \bar{x}=\bar{q}, \bar{x} \geq 0$ has a solution.

Proof. Suppose that $\bar{x} \geq 0$ solves the input-output pollution model. For each $\mathrm{j}$, there is an index $i_{j}, 1 \leq i_{j} \leq m_{j}$, such that

Define the row vectors

$$
\left(E^{j}-A^{j}\right)_{i_{j}} \bar{x}=q_{i_{j}}^{j}, \quad j=1,2, \ldots, n .
$$

where $i \in\left\{1, \ldots, m_{j}\right\}, 1 \leq i_{j} \leq m_{j}, j=1, \ldots, n$.

$$
M_{j}=\left(E^{j}-A^{j}\right)_{i_{j}}, \quad \bar{q}_{j}=q_{i_{j}}^{j}
$$

Let

$$
M=\left[\begin{array}{c}
M_{1} \\
\cdot \\
\cdot \\
\cdot \\
M_{n}
\end{array}\right], \bar{q}=\left[\begin{array}{c}
q_{1} \\
\cdot \\
\cdot \\
\cdot \\
q_{n}
\end{array}\right] .
$$

Then $M$ is a representative sub-matrix of $E-A$ and $\bar{x}$ satisfies $M \bar{x}=\bar{q}, \bar{x} \geq 0$ as required.

Conversely, suppose that there exists a representative sub-matrix $M$, a vector $\bar{q}$ defined from $q$ so as to conform to the rows of $M$, and a vector $\bar{x} \geq 0$ such that $M \bar{x}=\bar{q}$. Then there is an index $\alpha_{j}, 1 \leq \alpha_{j} \leq m_{j}$, such that

$$
\begin{gathered}
M_{j}=\left(E^{j}-A^{j}\right)_{\alpha_{j}}, j=1, \ldots, n \\
\bar{q}_{j}=q_{\alpha_{j}}^{j}, j=1, \ldots, n,
\end{gathered}
$$

by the definition of a representative sub-matrix. Thus given $A^{j}$ and $q^{j}$ there exists an $\bar{x}$ such that

$$
\begin{gathered}
\left(E^{j}-A^{j}\right)_{\alpha_{j}} \bar{x}=q_{\alpha_{j}}^{j}, \quad j=1, \ldots, n, \\
\bar{x} \geq 0
\end{gathered}
$$

for some index $\alpha_{j} \in\left\{1, \ldots, m_{j}\right\}$. This completes the proof.

The product selected by sector $\mathrm{j}$ for production is one whose pollution equation corresponds to row $j$ of $M$. The next theorem gives a condition under which the IOPM has a solution.

Theorem 2 The systems (3-5) have a solution if there exists a vector $\bar{x} \geq 0$ such that $(E-A) \bar{x}>0$.

Proof. Suppose that such a vector $\bar{x} \geq 0$ exists. Let $\bar{s}$ be a column vector of 1 s with n components. Let $\bar{y}=\bar{x}+\varepsilon \bar{s}$, $\varepsilon>0$. Then $\bar{y}>0$ and

$$
(E-A) \bar{y}=(E-A) \bar{x}+\varepsilon(E-A) \bar{s}>0,
$$

for sufficiently small $\varepsilon$.

From Equation (7), we have that $M \bar{y}>0$ for each representative sub-matrix $E-A$ of $M$. Since $E-A$ is a vertical block $Z$-matrix, $M$ is a square $Z$-matrix. By (Horn \& Johnson, 1991), we have that $M$ is invertible and that $M^{-1} \geq 0$. Thus, if $(E-A) \bar{x}>0$ for some $\bar{x} \geq 0$, the IOPM has a solution given by $\bar{y}=M^{-1} \bar{q} \geq 0$ as determined in Step 2 of the Algorithm. This completes the proof.

The following is an example that Leontief used to illustrate his model. We demonstrate the validity of our model by using the same example, but in pollution technology matrix format.

Example 1 (Leontief, 1970; 1986) Table 1 gives the Leontief's example in tabular form.

Table 1. Input-output table of a national economy with pollution (in physical/input-output units)

\begin{tabular}{llllll}
\hline & \multicolumn{3}{c}{ INTO } & External Demand & Total Demand \\
\cline { 2 - 6 } FROM & Agric. & Man. & & \\
\cline { 2 - 6 } & \multirow{2}{*}{ Agriculture } & 25 & 20 & 55 & 100 bushels of \\
& $(0.25$ & $0.40)$ & 30 & 50 yards of cloth \\
\cline { 2 - 6 } & \multirow{2}{*}{ Manufacture } & 14 & 6 & & 60 grams of solid \\
& $(0.14$ & $0.12)$ & & pollutants \\
\cline { 2 - 6 } & \multirow{2}{*}{ Pollutants } & .50 & .20 & & \\
\hline
\end{tabular}


Table 2 below is equivalent to Table 1 but in terms of pollution input-output coefficients.

Table 2. Input-Output table of pollution coefficients with demand quantities

\begin{tabular}{|c|c|c|c|c|c|}
\hline \multirow{4}{*}{ FROM } & & \multicolumn{2}{|c|}{ INTO } & Pollutants due to & Pollutants due to \\
\hline & & Agric. & Man. & external demand & total demand \\
\hline & Agriculture & 0.25 & 1.00 & 27.5 & $\begin{array}{l}50 \text { grams of } \\
\text { pollutants }\end{array}$ \\
\hline & Manufacture & $\begin{array}{l}0.056 \\
0.12\end{array}$ & & 6 & $\begin{array}{l}10 \text { grams of } \\
\text { pollutants }\end{array}$ \\
\hline
\end{tabular}

Define the production variables $x_{1}$ and $x_{2}$ by

$x_{1}=$ total amount of pollutants produced by the agricultural sector

$x_{2}=$ total amount of pollutants produced by the manufacturing sector

By substituting the data from Table 2 into Equations (3-5), we obtain

$$
\begin{gathered}
x_{1}-0.25 x_{1}-x_{2}=27.5 \\
x_{2}-0.056 x_{1}-0.12 x_{2}=6 \\
x_{1} \geq 0, x_{2} \geq 0
\end{gathered}
$$

Or

$$
\begin{gathered}
0.75 x_{1}-x_{2}=27.5 \\
-0.056 x_{1}+0.88 x_{2}=6 \\
x_{1} \geq 0, x_{2} \geq 0 .
\end{gathered}
$$

The solution to this system of linear equation is $x_{1}=50$ grams and $x_{2}=10$ grams, as expected. That is, the two sectors produce 60 grams of solid pollutants as Leontief showed in his example. Observe that Table 1 is the Leontief model while Table 2 corresponds to the new formulation.

Example 2 Application to the choice of products

The choice of technology models given in Ebiefung $(1998 ; 2010)$ can be used to select products for production. The model formulated in this paper can also be used to select products as illustrated in this example.

Consider an economy consisting of two sectors: agricultural and manufacturing. Let the pollution technology matrix be as follows:

\begin{tabular}{llllll}
\hline & & \multicolumn{2}{c}{ INTO } & Total & Pollutants \\
& Agric. & Man. & $\begin{array}{l}\text { Pollutants } \\
\text { allowed }\end{array}$ & $\begin{array}{l}\text { For external } \\
\text { Demands }\end{array}$ \\
\cline { 2 - 6 } FROM & $\begin{array}{l}\text { Agriculture } \\
\text { Wheat-bushel }\end{array}$ & 0.250 & 1.00 & 50 grams & 27.5 grams \\
& $\begin{array}{l}\text { Sugar-tons } \\
\text { Manufacturing }\end{array}$ & 0.240 & 1.50 & & \\
\cline { 2 - 6 } & Cloth-yards & 0.056 & 0.12 & 10 grams & 6 grams \\
Shoes-gross & 0.055 & 0.14 & & \\
\hline
\end{tabular}

Suppose that these products have made all production criteria set by the sectors. We want to find the product that each sector should select for production in order to meet both internal and external demands as well as satisfy pollution emission requirement.

Using the notation of the Algorithm, we define the following representative sub-matrices and the corresponding vectors.

$$
A_{1}=\left[\begin{array}{ll}
0.250 & 1.000 \\
0.056 & 0.120
\end{array}\right], A_{2}=\left[\begin{array}{ll}
0.250 & 1.000 \\
0.055 & 0.140
\end{array}\right], A_{3}=\left[\begin{array}{ll}
0.240 & 1.500 \\
0.056 & 0.120
\end{array}\right]
$$




$$
A_{4}=\left[\begin{array}{ll}
0.240 & 1.500 \\
0.055 & 0.140
\end{array}\right], q_{1}=q_{2}=q_{3}=q_{4}=\left[\begin{array}{c}
27.5 \\
6.0
\end{array}\right] .
$$

Solving the systems in Step 2 of the Algorithm, we obtain the following solutions in Table 3.

Table 3. Solutions to Example 2

\begin{tabular}{lcccc}
\hline Solution & $M_{1}, q_{1}$ & $M_{2, q_{2}}$ Parameter & $M_{3}, q_{3}$ & $M_{4, q_{3}}$ \\
\hline$(\mathrm{x}, \mathrm{y})$ & $(50.00,10.00)$ & $(50.2542,10.1907)$ & $(56.7715,10.4309)$ & $(57.1704,10.6630)$ \\
\hline $\begin{array}{l}\text { Total Pollution } \\
\text { by the economy }\end{array}$ & 60.00 grams & 60.4449 grams & 67.2024 grams & 67.8034 grams \\
\hline Item Selected & Wheat, Cloth & None & None & None \\
\hline
\end{tabular}

From Table 3, we see that the solution in column 2 satisfies the allowed pollutants limits. The sectors can decide to produce wheat and cloth (column 2) or wheat and shoes (column 3) depending on other criteria, which could include political considerations.

In Example 2, we assumed that the technologies used for the production of wheat and sugar produce the same amount of pollutants. This is only for convenience. The analysis will be true when pollutant levels are different. The same observation applies to the manufacturing sector.

\section{Computing Production Quantities}

The amount of pollutants produced determines the quantity of products to be manufactured by sector $j$. It is important for the sectors to translate pollutant quantities into production quantities.

For each $j$, let

$u_{j}=$ output of pollutants per unit output of product $i$ that sector $j$ has selected for production. Assume that $u_{j}>0$.

$L_{j}=$ total number of units of product $i$ that sector $j$ has decided to produce.

Theorem 3 The total amount of goods to be produced by sector $j$ is

$$
L_{j}=\sum_{k=1}^{n} u_{j}^{-1} a_{i k}^{j} x_{k}+u_{j}^{-1} \bar{q}_{j}
$$

where $j=1, \ldots, n, i \in\left\{1, \ldots, m_{j}\right\}$, and all other quantities are as defined before.

Proof. Since $a_{i k}^{j}$ is the units of pollutants by product $i$ from sector $j$ needed by sector $k$ to produce one unit of its pollutants, the quantity $a_{i k}^{j} x_{k}$ is the amount of pollutants by product $i$ produced by sector $j$ in order to satisfy the needs of sector $k$. Therefore, the quantity

$$
\frac{a_{i k}^{j} x_{k}}{u_{j}}=u_{j}^{-1} a_{i k}^{j} x_{k}
$$

is the number of units of product $i$ produced by sector $j$ for sector $k$. The sum $\sum_{k=1}^{n} u_{j}^{-1} a_{i k}^{j} x_{k}$ is the number of units of product $i$ produced by sector $j$ for all sectors of the economy. Since $\bar{q}_{j}=q_{i_{j}}^{j}, i \in\left\{1, \ldots, m_{j}\right\}$, is the amount of pollutants used to satisfy external demand, the total amount of product $i$ from sector $j$ is

$$
L_{j}=\sum_{k=1}^{n} u_{j}^{-1} a_{i k}^{j} x_{k}+u_{j}^{-1} \bar{q}_{j}
$$

This completes the proof.

Let $y_{j}$ be the amount of goods to be produced by sector $j$. If we define a diagonal matrix $U$ and a column vector $y$ by

$$
U=\left[\begin{array}{ccccc}
u_{1}^{-1} & 0 & \ldots & \ldots & 0 \\
0 & u_{2}^{-1} & 0 & \ldots & 0 \\
0 & \ldots & \ldots & \ldots & \ldots 0 \\
0 & \ldots & \ldots & \ldots & u_{n}^{-1}
\end{array}\right], y=\left[\begin{array}{c}
y_{1} \\
y_{2} \\
\ldots \\
y_{n}
\end{array}\right],
$$


respectively, then the amount of products to be produced by all sectors of the economy is given by

$$
y=U R x+U q,
$$

where $R$ is a representative sub-matrix of $A$ with rows corresponding to the rows of the products to be produced.

We now illustrate the use of Equation (9). If wheat and cloth are selected for production in Example 2, then

$$
U=\left[\begin{array}{cc}
0.5^{-1} & 0.0 \\
0.0 & 0.2^{-1}
\end{array}\right], R=\left[\begin{array}{cc}
0.25 & 1.00 \\
0.056 & 0.12
\end{array}\right], q=\left[\begin{array}{c}
27.5 \\
6.0
\end{array}\right], x=\left[\begin{array}{c}
50 \\
10
\end{array}\right]
$$

Hence,

$$
y=U R x+U q=(100,50) .
$$

Thus the agricultural sector should produce 100 bushel of wheat, and the manufacturing sector should produce 50 yards of cloth. These results are the same as those obtained by Leontief $(1970 ; 1986)$ as shown in Example 1.

\section{Conclusion}

A mathematical model that describes the flow of pollutants among different sectors of the economy is presented. It can be used to control the generation of industrial pollution in the sense that one cannot produce above an allowed pollution level. The system selects an optimal combination of products that the economy should produce in order to satisfy most demands and meet pollution emission requirements simultaneously. Conditions for existence of solutions and an algorithm for solving the model are provided.

Example 1 shows that the model is equivalent to the Leontief production model in the sense that it can be converted into the Leontief production model and versa. We use Example 2 to show an application of the model to product selection that meets specified pollution limits. For a given computed pollutant level, a technique for computing the corresponding production quantities is provided.

\section{References}

Bazaraa, M. S., \& Jarvis, J. J. (1977). Linear Programming and Network Flows. New York, NY: John Wiley.

Daly, H. E. (1968). On economics as a life science. The Journal of Political Economy, 76, $392-406$. http://dx.doi.org/10.1086/259412

Ebiefung, A. A. (1998). Choice of Technology and Partial Industrial Pollution Control. Proceedings of the $34^{\text {th }}$ Annual Meeting of the Southeastern Chapter of the Institute for Operations Research and the Management sciences, pp. 449- 451.

Ebiefung, A. A. (2010). Choice of Technology, Industrial Pollution, and the vertical linear complementarity problem. Global Journal of Mathematical Sciences, 9(2), 113-120.

Ebiefung, A. A., \& Kostreva, M. M. (1993). The Generalized Leontief Input-Output Model and its Application to the Choice of New Technology. Annals of Operations Research, 44, 161-172. http://dx.doi.org/10.1007/BF02061065

Ebiefung, A. A., \& Kostreva, M. M. (2003). Production Equilibrium Point in Multi-Unit Manufacturing Systems and the Vertical Linear Complementarity Problem. Annals of Operations Research, 124, $183-192$. http://dx.doi.org/10.1023/B:ANOR.0000004768.22040.55

Horn, R. A., \& Johnson, C. R. (1991). Topics in Matrix Analysis. Cambridge: Cambridge University Press. http://dx.doi.org/10.1017/CBO9780511840371

Leontief, W. W. (1985). The Choice of Technology. Scientific American, 252(6), 37-45. http://dx.doi.org/10.1038/scientificamerican0685-37

Leontief, W. W. (1986). Input-Output Economics (2 ${ }^{\text {nd }}$ edition). New York: Oxford University Press.

Leontief, W. W. (1970). Environmental repercussions and the economic structure: An input-output approach. The Review of Economics and Statistics, 52, 241- 260. http://dx.doi.org/10.2307/1926294

Leontief, W. W., \& Daniel, F. (1972). Air Pollution and the Economic Structure: Empirical Results of InputOutput Computations. In A. Brody and A.P. Carter (Eds.), Input-Output Techniques(pp. 9-23). Amsterdam: North-Holland. 
Miller, R. M., \& Blair, P. D. (1985). Input-Output Analysis: Foundations and Extensions. New Jersey: Prentice Hall.

Moore, S. A. (1981). Environmental repercussions and the economic structure: Some Further Comments. Review of Economics and Statistics, 36, 139-142. http://dx.doi.org/10.2307/1924229

Raa, T. T. (1995). Linear Analysis of Competitive Economies. LSE Handbook in Economics. New York, London: Harvester Wheatsheaf.

Steenge, A. E. (1999). Input-output theory and institutional aspects of environmental policy. Structural Change and Economic Dynamics, 10, 161-176. http://dx.doi.org/10.1016/S0954-349X(98)00064-2

Victor, P. A. (1972a). Economics of Pollution. London: Macmillian.

Victor, P. A. (1972b). Pollution: Economy and Environment. London: Allen and Unwin. 